\title{
Medical interventions to reduce motor vehicle collisions
}

\section{Donald A. Redelmeier MD MSHSR, Homer C. Tien MD MSC}

Competing interests: The funding organizations had no role in the design and conduct of the study; collection, management, analysis, and interpretation of the data; and preparation, review, or approval of the manuscript. All authors personal relationships or affiliations that could influence the decisions and work on this manuscript.

This article has been peer reviewed.

\section{Correspondence to:} Donald Redelmeier, dar@ices.on.ca

CMAJ 2014. DOI:10.1503 /cmaj.122001 have no financial or
$\mathrm{T}$ rauma caused by motor vehicle collisions is a common cause of death, accounting for more than 3000 deaths each day worldwide (about 7 of which occur in Canada). ${ }^{1}$ For each person who dies, an additional 80 people sustain injuries and 300 suffer financial losses. ${ }^{2}$ Trauma from motor vehicle collisions places a substantial load on emergency services and collectively costs Canada more than $\$ 100$ million per day in total societal expenditures. $^{3}$ About $50 \%$ of related deaths occur within minutes of impact, reinforcing the need for effective prevention strategies. ${ }^{4}$ Motor vehicle collisions are projected to be the fifth leading cause of death overall by the year 2020 and are currently the most common cause of death in Canada from birth to middle age. ${ }^{5,6}$

The high burden of this trauma contrasts with the topic's low visibility in medical school curricula and evidence-based medical literature, ${ }^{7}$ possibly because injury prevention does not typically entail prescribing a medication or performing a surgical procedure. In addition, the traditional view is that a physician's role is not to make patients virtuous, but to save them from the consequences of their vices. Thus, the management of trauma caused by motor vehicle collisions mostly emphasizes resuscitation and rehabilitation in the aftermath of the incident. ${ }^{8}$ The purpose of this article is to review what physicians can do to prevent this trauma for their patients. The evidence for this review comes pri- marily from rigorous observational studies and meta-analyses (Box 1).

\section{What societal interventions have been effective?}

Since the mass production of automobiles began, Canadian road safety has emphasized government regulations such as driver licensing, road patrols and vehicle standards. Additional enhancements to infrastructure have included the standardization of road signs, school crossing warnings, sidewalk segregation and highway design. The longest series of changes has focused on laws to prevent driving under the influence of alcohol, which became an indictable offence in 1925 and was revolutionized by curbside breath testing in 1962. Perhaps the most widely debated single change was the seat belt law introduced in 1976 (years after similar laws were introduced in some other countries). Most specific interventions have yielded a modest survival benefit (Table 1). ${ }^{9-18}$

Interventions for preventing trauma caused by motor vehicle collisions fall into a 4-part framework that has not changed in decades and mostly

\section{Box 1: Evidence used in this review}

We searched MEDLINE and PubMed using the following medical subject headings and text words: "motor vehicle crash," "traffic accident," "road trauma," "roadway collision,"

"transportation incident" and "driver safety." We restricted our review to literature published in English within the last 30 years. We validated our approach by checking the Cochrane Library headings "Orthopaedics and trauma, Prevention of road traffic injuries" and "Public health, Prevention of road traffic injuries." Further articles were identified by checking references, in addition to using the PubMed function "Search all related." We included trials that involved randomization or rigorous observational analytical methods. In addition, we included selected governmental background documents from the World Health Organization, Transport Canada and the Ontario Ministry of Transportation. 
excludes physicians: enforcement, engineering, economic forces and education..$^{19}$ Enforcement involves regulating behaviour using roadside police control (e.g., RIDE [Reduce Impaired Driving Everywhere] checkpoints to deter impaired driving and to allow police to verify passenger restrictions, roadway restrictions and alcohol restrictions for new drivers under graduated licensing programs).$^{20}$ Engineering emphasizes changes to roads or vehicles for collision avoidance and protection (e.g., divided highways and collapsible steering columns). ${ }^{21}$ Economic forces include incentives that reduce total driving or specific driving patterns (e.g., economic recessions and fuel prices). ${ }^{22}$ Educational interventions involve promoting safety messaging (e.g., broadcast warnings and formal driver education). ${ }^{23}$

\section{What restrictions are recommended for reversible medical conditions?}

Effective modern medical care reduces risk even if physicians are unaware of the benefits to road safety. For example, correcting a patient's hypothyroidism might indirectly prevent the patient from becoming an impaired driver; temporary cautions against operating heavy machinery are standard when treatment involves an invasive procedure, systemic chemotherapy, brain radiotherapy or sedative medications; and guidelines for care after cervical spine surgery advise against driving until neck mobility is sufficiently restored. ${ }^{24}$ Each of these short-term medical restrictions are based on blatant clinical situations, have not been tested in formal trials and are accepted practice. ${ }^{25}$

Physicians have no evidence from randomized controlled trials to guide their decisions concerning the duration of temporary restrictions on driving. Instead, prevailing recommendations reflect expert opinion and clinical experience. ${ }^{24}$ Anesthesia guidelines caution against patients driving for 3-12 hours after having a procedure that involved sedation. ${ }^{26}$ Cardiology guidelines caution against patients driving for 2-7 days after angioplasty. ${ }^{27}$ Surgery guidelines caution against patients driving for 4-8 weeks after a major cardiac procedure. ${ }^{28}$ These landmarks might serve as guides for clinicians in other settings (e.g., recommending

Table 1: Interventions and their effects on mortality in motor vehicle collisions

\begin{tabular}{|c|c|c|}
\hline Intervention & Effect of intervention & $\operatorname{RR}(95 \% \mathrm{Cl})$ \\
\hline Use of seat belts & $\begin{array}{l}\text { Reduced mortality for vehicle occupants using a seat } \\
\text { belt when compared with unbelted passengers in the } \\
\text { same vehicle }\end{array}$ & $0.39(0.37-0.41)$ \\
\hline $\begin{array}{l}\text { Conviction for traffic } \\
\text { infraction }\end{array}$ & $\begin{array}{l}\text { Reduced risk of driver being involved in a fatal crash } \\
\text { during the first month after a conviction for a traffic } \\
\text { infraction }{ }^{10}\end{array}$ & $0.65(0.55-0.80)$ \\
\hline Use of air bags & $\begin{array}{l}\text { Reduced mortality attributed to airbag use for drivers } \\
\text { in head-on collision compared with other driver in the } \\
\text { same collision }{ }^{11}\end{array}$ & $0.71(0.58-0.87)$ \\
\hline $\begin{array}{l}\text { Use of helmets by } \\
\text { motorcyclists }\end{array}$ & $\begin{array}{l}\text { Reduced mortality for motorcyclists wearing helmets } \\
\text { in a crash compared with passengers, as analyzed by } \\
\text { double pairs }{ }^{12}\end{array}$ & $0.72(0.64-0.80)$ \\
\hline Graduated licensing & $\begin{array}{l}\text { Reduced risk of a fatal crash for } 16 \text {-year-old drivers } \\
\text { who have graduated licences compared with those } \\
\text { with regular licences }{ }^{13}\end{array}$ & $0.74(0.65-0.84)$ \\
\hline $\begin{array}{l}\text { Treatment at level } 1 \\
\text { trauma centres }\end{array}$ & $\begin{array}{l}\text { Reduced in-hospital mortality for patients treated at } \\
\text { level } 1 \text { trauma centres compared with patients at } \\
\text { nontrauma centres }{ }^{14}\end{array}$ & $0.80(0.66-0.98)$ \\
\hline Traffic-calming measures & $\begin{array}{l}\text { Reduced fatal and nonfatal collisions on traffic- } \\
\text { calmed roadways before and after intervention }{ }^{15}\end{array}$ & $0.85(0.75-0.96)$ \\
\hline $\begin{array}{l}\text { Daytime running } \\
\text { headlights }\end{array}$ & $\begin{array}{l}\text { Reduced odds of multivehicle daytime collision before } \\
\text { and after implementation of daytime running lights }{ }^{16}\end{array}$ & $0.89(0.85-0.92)$ \\
\hline Increased speed limits & $\begin{array}{l}\text { Reduction in fatality after increased speed limits } \\
\text { compared with same roads before increased speed } \\
\text { limits }^{17}\end{array}$ & 0.97 (NA) \\
\hline Driver education & $\begin{array}{l}\text { No decrease in serious motor vehicle collisions with } \\
\text { driver education from meta-analysis of randomized } \\
\text { trials }\end{array}$ & $0.98(0.96-1.01)$ \\
\hline
\end{tabular}


that ophthalmology patients not drive for a few hours after iris dilation). The lack of scientific evidence, however, implies that judgment is necessary, dissenting opinions are inevitable, and conflicts are difficult to resolve. Various Internet resources are available to guide physician and patient decision-making (Box 2).

\section{Box 2: Additional resources \\ CMA driver's guide: determining medical fitness to operate motor vehicles, 8th edition \\ - A comprehensive review compiled by Canadian leaders and targeted at physicians. Available: www.cma.ca/driversguide \\ Ontario Road Safety annual reports \\ - Annual surveillance reports for Ontario providing detailed data on the burden of losses from motor vehicle trauma. Available: www.mto.gov.on.ca/english /safety/orsar/ \\ Transport Canada \\ - The Canadian government agency focusing on transportation, including health losses. \\ Available: www.tc.gc.ca/eng/menu.htm \\ Global plan for the decade of action for road safety 2011-2020 \\ - A global summary of motor vehicle trauma from an international perspective. Available: www.who.int/roadsafety /decade_of_action/plan/en/index.html \\ Physician's guide to assessing and counseling older drivers, 2nd edition \\ - A comprehensive review compiled by American authorities with some nuances for Canadian physicians. \\ Available: www.ama-assn.org/resources /doc/public-health/older-drivers-guide.pdf}

Table 2: Selected diseases, risks and effectiveness of medical warnings in preventing motor vehicle collisions

\begin{tabular}{|c|c|c|c|}
\hline \multirow[b]{2}{*}{ Disease } & \multicolumn{2}{|c|}{ Event rate* } & \multirow[b]{2}{*}{$\operatorname{RR}(95 \% \mathrm{Cl})$} \\
\hline & At baseline & $\begin{array}{c}\text { After } \\
\text { warning }\end{array}$ & \\
\hline Dementia & 2.92 & 0.86 & $0.31(0.18-0.58)$ \\
\hline Stroke & 3.5 & 1.15 & $0.32(0.19-0.60)$ \\
\hline Depression & 8.75 & 3.6 & $0.38(0.25-0.60)$ \\
\hline Syncope & 5.91 & 2.95 & $0.49(0.38-0.64)$ \\
\hline Epilepsy & 5.92 & 3.23 & $0.53(0.36-0.78)$ \\
\hline Diabetes & 4.49 & 2.71 & $0.59(0.43-0.82)$ \\
\hline Sleep disorder & 6.1 & 3.85 & $0.62(0.46-0.85)$ \\
\hline Alcoholism & 7.24 & 4.91 & $0.64(0.46-0.91)$ \\
\hline \multicolumn{4}{|c|}{$\begin{array}{l}\text { Note: Data adapted from Redelmeier and colleagues. }{ }^{30} \mathrm{Cl}=\text { confidence interval, } \mathrm{RR}=\text { risk } \\
\text { ratio. } \\
\text { *The benchmark rate in the general population is about } 1.96 \text { serious crashes per } 1000 \text { drivers } \\
\text { annually. }\end{array}$} \\
\hline
\end{tabular}

\section{How should we address drivers with chronic health conditions?}

Physicians sometimes give explicit medical warnings to patients with chronic diseases that may render them potentially unfit to drive. Canadian programs began in 1968 focusing on seizures, syncope and other conditions marked by a sudden loss of consciousness. ${ }^{29}$ The most recent epidemiologic study suggests that such warnings yield a $45 \%$ reduction in serious crashes (95\% confidence interval [CI] 36-52). For example, drivers with alcoholism have a significantly lower annual serious crash rate after receiving such a warning (Table 2) ${ }^{30}$ Reductions in crash rates after physicians' warnings are large and sustained, but they are also accompanied by increases in patient dissatisfaction and depression. Warnings are equally reliable regardless of whether the responsible physician is a generalist or specialist.

Previous research shows that medical warnings are not completely effective at preventing crashes. A total of 11 studies are available from 1968 to $2009,{ }^{31-41}$ and they rely primarily on statistical modelling, ecologic comparisons, case-control pairings, time series analysis or survey designs. Overall, 4 of the 11 studies report no significant effect from warnings, 3 report modest benefits, and the remaining 4 report ambiguous findings. The 2 most rigorous studies from Canada showed a relative risk reduction of $13 \%$ (95\% CI 6-20) and $32 \%$ (95\% CI 17-47) for road crashes. ${ }^{35,39}$ The variable effectiveness of medical warnings suggests that patients do not always follow medical advice. ${ }^{42}$

The essential components of an effective medical warning are unknown and rarely scrutinized owing to the privacy of doctor-patient relationships. In Ontario, physician warnings to drivers deemed medically unfit to drive generally involve direct discussion with the patient and a cursory notification to the driver-licensing agency. A warning does not necessarily lead to a suspended licence. However, a warning can mean that the patient's vehicle insurance might be denied in the event of a serious crash (tantamount to the patient driving with no insurance). Untangling the effects of each component of a medical warning (doctor, government, insurer) is problematic given the additional indirect influences from family and acquaintances.

Most chronic diseases are not characterized by a sudden loss of consciousness and do not always prompt physicians to consider a patient's fitness to drive. ${ }^{43}$ As such, less than $1 \%$ of adult patients receive a medical warning about driving, a rate substantially below that of the Canadian 
prevalence of single chronic diseases, such as alcoholism. ${ }^{44}$ In response, 7 provinces currently mandate warnings (with the exceptions of Alberta, Quebec and Nova Scotia), and 1 province (Ontario) further encourages physicians through a financial incentive $(\$ 36.25$ per warning). ${ }^{45,46}$ Such incentives doubled the number of warnings given by physicians to patients in Ontario (Judy Taggart, Ministry of Transportation, personal communication, Aug. 6, 2013). Whether such programs might be effective in other regions is unknown.

\section{Should drivers at indeterminate risk undergo screening?}

Many patients have an equivocal risk of driving impairment because of multiple chronic diseases, fluctuating severity of disease or uncertain functional ability. On-road driver testing has been proposed for the evaluation and assistance of these patients. However, such testing is controversial owing to its uncertain effectiveness and the high cost and stress to patients. No large randomized controlled trials have examined whether on-road testing reduces serious crashes; moreover, results from small case series are discouraging. ${ }^{47-50}$ The lack of consensus for on-road driver testing has led to a variety of less elaborate in-clinic assessment tools, including the CANDRIVE mnemonic for conditions that warrant screening for fitness to drive (Table 3 ) ${ }^{51}$ which is currently undergoing clinical trials..$^{52-55}$

The medical disorder with the most research concerning in-clinic screening for driver safety is dementia. The largest meta-analysis of in-clinic cognitive tests to predict driving ability included 27 studies and identified only modest correlations after excluding patients who did not have dementia (correlation coefficients -0.06 to $0.31) .^{56}$ The most recent systematic review of inclinic cognitive predictors included 16 studies and concluded that data were inadequate to base fitness-to-drive guidelines solely on the scientific literature. ${ }^{57}$ For Canada, the CMA driver's guide: determining medical fitness to operate motor vehicles remains the resource of choice for inclinic assessments. ${ }^{24}$ Although lengthy and sometimes vague, the guide provides a comprehensive approach for screening for diverse medical disorders that could impair driving ability (Table 4) ${ }^{24}$

Some patients have already been involved in a motor vehicle collision and may be at risk of another event, even if peoples' natural tendency is to blame the other driver. Such cases might be more common than physicians generally realize - each year, about $2 \%$ of Canadians are involved in a collision. ${ }^{58}$ Thus, physicians may want to ask patients about motor vehicle collisions when eliciting a medical history.

The strongest data on secondary prevention focuses on brief alcohol interventions for survivors of crashes, which yield a reduction in recidivism of about $50 \% .^{59,60}$ Other options of uncertain effectiveness in the aftermath of a col-

Table 3: The CANDRIVE mnemonic

\begin{tabular}{|ll|}
\hline Domain & \multicolumn{1}{c}{ Examples } \\
\hline Cognitive impairment & Dementia, depression, inattention \\
\hline Acute (fluctuating) Illness & Delirium, pre-syncope, arrhythmia \\
\hline Neuromuscular disease & Parkinson disease, hypoglycemia \\
\hline Drugs & Benzodiazepines, opioids \\
\hline Record & Collisions, infractions \\
\hline In-vehicle experiences & Near incidents, vehicle damage \\
\hline Vision & Night vision, field defects \\
\hline Ethanol use & Mixing alcohol with driving \\
\hline
\end{tabular}

Note: Adapted from Molnar and colleagues. ${ }^{51}$

Table 4: Health conditions that may contribute to risk of collision fatality

\begin{tabular}{|c|c|c|}
\hline Health condition & Mandatory testing & Method for testing* \\
\hline \multicolumn{3}{|l|}{ Vision } \\
\hline Visual acuity loss & Yest & Visual acuity test \\
\hline Visual field defect & $\begin{array}{l}\text { Commercial divers } \\
\text { only }\end{array}$ & Visual field test \\
\hline Diplopia & No & $\begin{array}{l}\text { Examination by a } \\
\text { physician }\end{array}$ \\
\hline \multicolumn{3}{|l|}{ Cognition } \\
\hline Alcohol dependence & No & Questionnaire \\
\hline Sleep disorder & No & Sleep study \\
\hline Dementia & No & Cognitive test \\
\hline Psychiatric disorder & No & $\begin{array}{l}\text { Examination by a } \\
\text { physician }\end{array}$ \\
\hline Seizure & No & Electroencephalography \\
\hline Concussion & No & Cognitive test \\
\hline \multicolumn{3}{|l|}{ Miscellaneous } \\
\hline Diabetes mellitus & $\begin{array}{l}\text { Commercial } \\
\text { drivers only }\end{array}$ & $\begin{array}{l}\text { Glucose diary, } \\
\text { laboratory investigation } \\
\text { (acetated hemoglobin } \\
\text { level) }\end{array}$ \\
\hline Hearing loss & $\begin{array}{l}\text { Commercial } \\
\text { drivers only }\end{array}$ & Audiometry \\
\hline Aortic aneurism & No & Imaging study \\
\hline \multicolumn{3}{|c|}{$\begin{array}{l}\text { Note: Adapted from the CMA's driver's guide: determining medical fitness to operate motor } \\
\text { vehicles, } 8 \text { th edition. }{ }^{24} \\
\text { *Specific methods for screening are generally based on criteria for commercial drivers. } \\
\text { †All provinces and territories require testing for visual acuity and also impose a statutory } \\
\text { duty on physicians relating to warning patients who are potentially unfit to drive. The duty } \\
\text { to warn and report is mandatory in all provinces and territories, with the exceptions of } \\
\text { Alberta, Nova Scotia and Quebec. }\end{array}$} \\
\hline
\end{tabular}


lision include screening for glaucoma, drug abuse, psychiatric disorders and dementia. ${ }^{61,62}$

\section{Who merits special consideration of risk for motor vehicle trauma?}

Several populations merit special attention as particularly large contributors to motor vehicle trauma or particularly missed by general countermeasures. Heavy alcohol consumption contributes to one-third of total crashes, and people who consume large quantities of alcohol are likely to make frequent visits to physicians. ${ }^{21}$ Young Canadians, including infants with improperly installed car seats, children engaging in careless behaviour and teenagers with attention deficits, are overrepresented in serious road crashes despite previous contacts with physicians. ${ }^{63}$ Adults whose lifestyles include thrillseeking adventures such as off-roading are resistant to general countermeasures. ${ }^{64}$ Whether these groups would be responsive to prevention strategies from physicians is unknown.

Truck drivers and other commercial vehicle operators contribute to about 1 in 5 fatal motor vehicle crashes in Canada, mostly due to the quantity of time they spend on the road. However, the actual fatality rate per billion vehiclekilometers for this population is about one-third of that seen for all vehicles in Canada (2.5 v. 7.2, respectively). ${ }^{65}$ The safety profile of commercial drivers is a reflection of multiple countermeasures, including government regulation of work hours, licensing requirements, automatic speed limiters, on-board recorders and professional training. In addition, commercial drivers require physician certifications, similar to those required for pilots. ${ }^{66}$ However, a considerable problem

\section{Box 3: Fictional case}

A 52-year-old chef presents with a history of weakness in his left hand, which has now resolved. The patient has poorly controlled hypertension $(200 / 100 \mathrm{~mm} \mathrm{Hg})$ and is a heavy smoker (1 pack of cigarettes/d). The patient consumes alcohol ( 1 case of beer/wk) and reports using marijuana. The patient drives 40 minutes per day to work and was in a vehicle collision 3 years ago, which led to to chronic neck pain. He has no other medical history and dislikes visiting physicians.

Computed tomographic imaging of the head shows lacunar infarcts of diverse ages. How can you reduce the patient's risk of further motor vehicle injury?

The patient has multiple vascular risk factors and had a recent transient ischemic attack. As a physician, you have a duty to warn him about safe driving. The patient may resume driving if a neurologic assessment shows no residual deficits and the underlying causes have been addressed (including impaired driving). A warning might influence subsequent adherence to follow-up and lifestyle recommendations. Having the patient undergo screening for fitness to drive would be debatable. Reporting this patient to licensing agencies would be mandatory in some Canadian provinces. among commercial drivers is fatigue, sometimes due to a medical sleep disorder, with prevalences ranging from $10 \%$ to $78 \%$ in some studies. ${ }^{67,68}$

\section{Unanswered questions}

Most ongoing research on driving focuses on what patients can do for themselves rather than on data to guide clinicians. The Strategic Highway Research Program 2 (SHRP 2) Naturalistic Driving Study is the largest continuing field study using specially instrumented vehicles $(n=$ 2360) to investigate how driver inattention and other behaviours might contribute to crash risk. ${ }^{69}$ The Candrive Cohort Study of Older Drivers is perhaps the largest Canadian research effort, following older drivers $(n=1000)$ over 5 years to evaluate clinical factors that potentially predict unsafe driving. ${ }^{70}$ The DRUID Study (Driving under the Influence of Drugs, Alcohol and Medicines) involves drivers in 18 European countries $(n=50000)$ to assess the prevalence of psychoactive substances in contributing to crashes. ${ }^{71}$ In addition, small studies scattered over a variety of commercial domains examine potential improvements in vehicle technology.

Many questions remain for future research. Identifying risk factors for motor vehicle collisions is problematic, because such studies require intercepting motorists and screening for background prevalence rates among those who do not have collisions (an obstacle even in assessing the risks from alcohol). Determining the importance of medical conditions is also difficult owing to behavioural offsets, in which patients self-regulate their driving to compensate for their deficits. The validation of screening interventions is similarly limited by selecting participants who might be inherently health-conscious and safety-minded. Thus, clinicians have no strong data to support asking even rudimentary questions, such as "When is it unsafe for my patient to drive?" and "Which screening interventions for safe driving are cost effective?"

\section{Summary}

Trauma attributable to motor vehicle collisions is a widespread cause of morbidity and death. Most Canadian patients will be in a serious collision at least once in their lifetime. ${ }^{72}$ Practising physicians might help prevent some death and morbidity using effective resuscitation in the aftermath of a crash, advocating general countermeasures toward road safety and issuing medical warnings to potentially unfit drivers, in addition to using unproven indirect strategies (see illustrative case in Box 3). The past half-century 
has shown an improvement of about 30\%-50\% in total traffic fatalities through a combination of interventions that each had modest effectiveness. ${ }^{73}$ The role for physicians in preventing collisions may expand given the shift in age demographics and ongoing advances in convenient and reliable motor vehicles.

\section{References}

1. The top 10 causes of death: the 10 leading causes of death in the world, 2000 and 2011. Geneva (Switzerland): World Health Organization; updated 2013 (accessed 2011 June 9); Available: www.who.int/mediacentre/factsheets/fs 310/en/index.html

2. Blincoe L, Seay A, Zaloshnja E, et al. The economic impact of motor vehicle crashes 2000. Washington (DC): US Department of Transportation, National Highway Traffic Safety Administration (NHTSA); 2002.

3. Analysis and estimation of the social cost of motor vehicle collisions in Ontario (2007 report). Ottawa (ON): Transport Canada; 2007. Available: www.tc.gc.ca/eng/roadsafety/tp-tp14800-menu -159.htm (accessed 2010 Nov. 20).

4. Reducing the severity of road injuries through post impact care. Brussels (Belgium): European Transport Safety Council; 1999.

5. Mathers CD, Loncar D. Projections of global mortality and burden of disease from 2002 to 2030. PLoS Med 2006;3:e442.

6. Statistical abstract of the United States 2012: the national data book-2012- [Table 121]. Washington (DC): US Department of Commerce; 2013.

7. Redelmeier DA, McLellan BA. Modern medicine is neglecting road traffic crashes. PLOS Medicine 2013;10(6):e100146.

8. Redelmeier DA, Yarnell CJ. Lethal misconceptions: interpretation and bias in studies of traffic deaths. J Clin Epidemiol 2012; 65:467-73.

9. Cummings P, Wells JD, Rivara FP. Estimating seat belt effectiveness using matched-pair cohort methods. Accid Anal Prev 2003 35:143-9.

10. Redelmeier DA, Tibshirani RJ, Evans L. Traffic-law enforcement and risk of death from motor-vehicle crashes: casecrossover study. Lancet 2003;361:2177-82.

11. Crandall CS, Olson LM, Sklar DP. Mortality reduction with air bag and seat belt use in head-on passenger car collisions. Am J Epidemiol 2001;153:219-24.

12. Evans L, Frick MC. Helmet effectiveness in preventing motorcycle driver and passenger fatalities. Accid Anal Prev 1988;20: 447-58.

13. Masten SV, Foss RD, Marshall SW. Graduated driver licensing and fatal crashes involving 16- to 19 -year-old drivers. JAMA 2011;306:1098-103

14. MacKenzie EJ, Rivara FP, Jurkovich GJ, et al. A national evaluation of the effect of trauma-center care on mortality. N Engl J Med 2006;354:366-78.

15. Bunn F, Collier T, Frost C, et al. Area-wide traffic calming for preventing traffic-related injuries. Cochrane Database Syst Rev 2003; (1):CD003110.

16. Elvik R. A meta-analysis of studies concerning the safety effects of daytime running lights on cars. Accid Anal Prev 1996;28:685-94.

17. Friedman LS, Hedeker D, Richter ED. Long-term effects of repealing the national maximum speed limit in the United States. Am J Public Health 2009;99:1626-31.

18. Ker K, Roberts I, Collier T, et al. Post-licence driver education for the prevention of road traffic crashes: a systematic review of randomized controlled trials. Accid Anal Prev 2005;37:305-13.

19. Kellermann AL, Todd KN. Injury control. In Tintinalli JE, Kelen GD, Stapczynksi JS, editors. Emergency medicine: a comprehensive study guide. 5th ed. New York (NY): McGraw Hill; 2000.

20. Redelmeier DA, Tibshirani RJ, Evans L. Traffic-law enforcement and risk of death from motor-vehicle crashes: casecrossover study. Lancet 2003:361:2177-82.

21. Evans L. Traffic safety. Bloomfield (MI): Science Serving Society; 2004.

22. Grabowski DC, Morrisey MA. Gasoline prices and motor vehicle fatalities. J Policy Anal Manage 2004;23:575-93.

23. Mayhew DR, Simpson HM. The safety value of driver education and training. Inj Prev 2002;8(Suppl 2):ii3-7.

24. Dow J, Simpson C, Molnar F, et al., editors. CMA driver's guide: determining medical fitness to operate motor vehicles. 8th ed. Ottawa (ON): Canadian Medical Association; 2012.

25. Giddins GE, Hammerton A. Doctor when can I drive? A medical and legal view of the implications of advice on driving after injury or operation. Injury 1996;27:495-7.
26. Tucker PF, Chilvers CR. Fitness to drive after intravenous sedation and general anaesthesia: a literature review. Australasian Anaesthesia 2003:27-40. Available: www.qld.anzca.edu.au /anzca/resources/college-publications/pdfs/books-and-publications /Australasian\%20Anaesthesia/australasian-anaesthesia-2003/27\% 20TUCKER.pdf (accessed 2013 May 14).

27. Consensus conference, Canadian Cardiovascular Society: assessment of the cardiac patient for fitness to drive. Can J Cardiol 1992;8:406-19.

28. Carr DB, Schwartzberg JG, Manning L, et al. Physician's guide to assessing and counseling older drivers. 2 nd ed. Chicago (IL) American Medical Association and Washington (DC): National Highway Traffic Safety Administration; 2010.

29. Brison R, Bosco C. Examining issues related to physicians' duty to report unfit drivers in Ontario. Ont Med Rev 1997;64:17-22.

30. Redelmeier DA, Yarnell CJ, Thiruchelvam D, et al. Physicians' warnings for unfit drivers and the risk of trauma from road crashes. N Engl J Med 2012;367:1228-36.

31. Crancer A, McMurray L. Accident and violation rates of Washington's medically restricted drivers. JAMA 1968;205:272-6.

32. Guibert R, Duarte-Franco E, Ciampi A, et al. Medical conditions and the risk of motor vehicle crashes in men. Arch Fam Med 1998; 7:554-8.

33. Simpson CS, Klein GJ, Brennan FJ, et al. Impact of a mandatory physician reporting system for cardiac patients potentially unfit to drive. Can J Cardiol 2000;16:1257-63.

34. Vernon DD, Diller EM, Cook LJ, et al. Evaluating the crash and citation rates of Utah drivers licensed with medical conditions, 1992-1996. Accid Anal Prev 2002;34:237-46.

35. Marshall SC, Spasoff R, Nair R, et al. Restricted driver licensing for medical impairments: Does it work? CMAJ 2002;167:747-51.

36. Drazkowski JF, Fisher RS, Sirven JI, et al. Seizure-related motor vehicle crashes in Arizona before and after reducing the driving restriction from 12 to 3 months. Mayo Clin Proc 2003;78:819-25.

37. McLachlan RS, Starreveld E, Lee MA. Impact of mandatory physician reporting on accident risk in epilepsy. Epilepsia 2007; 48:1500-5.

38. Meuser TM, Carr DB, Ulfarsson GF. Motor-vehicle crash history and licensing outcomes for older drivers reported as medically impaired in Missouri. Accid Anal Prev 2009;41:246-52.

39. Caragata Nasvadi G, Wister A. Do restricted driver's licenses lower crash risk among older drivers? a survival analysis of insurance data from British Columbia. Gerontologist 2009;49: 474-84.

40. Braitman KA, Chaudhary NK, McCartt AT. Restricted licensing among older drivers in Iowa. J Safety Res 2010;41:481-6.

41. Eggert S, Thali MJ, Pfäffli M. Discretionary medical reporting of potentially unfit drivers: a questionnaire-based survey in southeast Switzerland. Int J Legal Med 2012;126:71-8.

42. Williams SB, Whitlock EP, Edgerton EA, et al.; US Preventive Services Task Force. Counseling about proper use of motor vehicle occupant restraints and avoidance of alcohol use while driving: a systematic evidence review for the US Preventive Services Task Force. Ann Intern Med 2007;147:194-206.

43. Rizzo M. Impaired driving from medical conditions: a 70-yearold man trying to decide if he should continue driving. JAMA 2011;305:1018-26.

44. Redelmeier DA, Venkatesh V, Stanbrook M. Mandatory reporting by physicians of patients potentially unfit to drive. Open Med 2008;2:e8-17.

45. Schedule of benefits and fees. Toronto (ON): Ontario Ministry of Health and Long-Term Care; 2011. Available: www.health .gov.on.ca/english/providers/program/ohip/sob/physserv/a_ consul.pdf (accessed 2011 Aug. 4).

46. Ontario Medical Association. OMA-MOHLTC agreement update: Physician Services Committee progress report. Ont Med Rev 2006;73:29-43.

47. Turnbull G. Is DriveABLE workABLE? [letter]. BCMJ 2011;53: 68.

48. Dobbs AR. DriveABLE responds [letter]. BCMJ 2011;53:68

49. Leproust S, Lagarde E, Salmi LR. Systematic screening for unsafe driving due to medical conditions: still debatable. BMC Public Health 2008;8:27.

50. Hoggarth PA, Innes CR, Dalrymple-Alford JC, et al. Prospective study of healthy older drivers: no increase in crash involvement or traffic citations at 24 months following a failed on-road assessment. Transp Re, Part F Traffic Psychol Behav 2012;16:73-80.

51. Molnar FJ, Byszewski AM, Marshall SC, et al. In-office evaluation of medical fitness to drive: practical approaches for assessing older people. Can Fam Physician 2005;51:372-9.

52. Molnar FJ, Patel A, Marshall SC, et al. Clinical utility of officebased cognitive predictors of fitness to drive in persons with dementia: a systematic review. J Am Geriatr Soc 2006;54:1809-24.

53. Classen S, Horgas A, Awadzi K, et al. Clinical predictors of 
older driver performance on a standardized road test. Traffic Inj Prev 2008;9:456-62

54. Mathias JL, Lucas LK. Cognitive predictors of unsafe driving in older drivers: a meta-analysis. Int Psychogeriatr 2009;21:637-53.

55. O'Connor MG, Kapust LR, Lin B, et al. The 4Cs (crash history, family concerns, clinical condition, and cognitive functions): a screening tool for the evaluation of the at-risk driver. J Am Geriatr Soc 2010;58:1104-8.

56. Reger MA, Welsh RK, Watson GS, et al. The relationship between neuropsychological functioning and driving ability in dementia: a meta-analysis. Neuropsychology 2004;18:85-93.

57. Molnar FJ, Patel A, Marshall SC, et al. Clinical utility of office-based cognitive predictors of fitness to drive in persons with dementia: a systematic review. J Am Geriatr Soc 2006;54: 1809-24.

58. Ontario road safety annual report. Toronto $(\mathrm{ON})$ : Ontario Ministry of Transportation; 2009. Available: www.mto.gov.on.ca/english /safety/orsar/orsar09/index.shtml (accessed 2013 Oct. 22).

59. Gentilello LM, Rivara FP, Donovan DM, et al. Alcohol interventions in a trauma center as a means of reducing the risk of injury recurrence. Ann Surg 1999;230:473-80.

60. Schermer CR, Moyers TB, Miller WR, et al. Trauma center brief interventions for alcohol disorders decrease subsequent driving under the influence arrests. J Trauma 2006;60:29-34.

61. McGwin G, Mays A, Joiner W, et al. Is glaucoma associated with motor vehicle collision involvement and driving involve- ment and driving avoidance? Invest Ophthalmol Vis Sci 2004;45 3934-9.

62. Charlton JH, Koppel S, O'Hare M, et al. Influence of chronic illnes. on crash involvement of motor vehicle drivers. Victoria (AU): Monash Univesity Accident Research Centre; 2004. Available: www.monash.edu.au/miri/research/reports/muarc213.html (accessed 2012 Nov. 21)

63. Redelmeier DA, Chan WK, Lu H. Road trauma in teenage male youth with childhood disruptive behavior disorders: a population-based analysis. PLoS Med 2010;7:e1000369.

64. Helmkamp JC. Injuries and deaths and the use of all-terrain vehicles. N Engl J Med 2000;343:1733-4.

65. Civil aviation medicine. Ottawa $(\mathrm{ON})$ : Transport Canada. Available: www.tc.gc.ca/eng/roadsafety/tp-tp15145-1201.htm (accessed 2012 Nov. 21).

66. Road safety in Canada. Ottawa (ON): Transport Canada. Available: www.tc.gc.ca/CivilAviation/Cam/ (accessed 2012 Nov. 27).

67. Stoohs RA, Bingham LA, Itoi A, et al. Sleep and sleepdisordered breathing in commercial long-haul truck drivers. Chest 1995; 107:1275-82.

68 Tregear S, Reston J, Schoelles K, et al. Obstructive sleep apnea and risk of motor vehicle crash: systematic review and metaanalysis. J Clin Sleep Med 2009;5:573-81.

69. Transportation Research Board. The SHRP2 Naturalistic Driving Study. Washington (DC): Strategic Highway Research Program. Available: www.trb.org/StrategicHighwayResearchProgram 2SHRP2/Pages/The-SHRP-2-Naturalistic-Driving-Study-472.aspx (accessed 2012 Nov. 27).

70. Candrive: driving research for older adults. Ottawa $(\mathrm{ON})$ Ottawa Hospital Research Institute. Available: www.candrive.ca /en/research-projects/42.html (accessed 2012 Nov. 27).

71. DRUID - Driving under the influence of drugs, alcohol and medicines. Germany: Federal Highway Research Institute; 2007. Available: www.druid-project.eu/cln_031/nn_107534/Druid/EN/ about-DRUID/about-DRUID-node.html?_nnn=true (accessed 2012 Nov. 27).

72. Redelmeier DA, Bayoumi AM. Time lost by driving fast in the United States. Med Decis Making 2010;30:E12-9.

73. The global impact. In: World report on road traffic injury prevention. Geneva (Switzerland): World Health Organization; 2004. Available: www.who.int/violence_injury_prevention /publications/road_traffic/world_report/chapter2.pdf (accessed 2012 Nov. 21).

Affiliations: Department of Medicine, University of Toronto; Evaluative Clinical Sciences, Sunnybrook Research Institute (Redelmeier); Canadian Forces Health Services; Department of Surgery (Tien), Sunnybrook Health Sciences Centre, Toronto, Ont.

Contributors: Donald Redelmeier drafted the article. Both of the authors revised the article for important intellectual content and approved the final version submitted for publication.

Acknowledgements: This project was supported by the Canada Research Chair in Medical Decision Sciences and the Canadian Institutes of Health Research. The views expressed in this paper are those of the authors and do not necessarily reflect the Ontario Ministry of Health. The authors thank William Chan, Christopher Kandel, Andrew Lustig, Sharon May, John Staples, Tom Stelfox, Adina Weinerman, Jason Woodfine and Christopher Yarnell for their helpful comments.

Disclaimer: This study was supported by the Institute for Clinical Evaluative Sciences (ICES), which is funded by an annual grant from the Ontario Ministry of Health and LongTerm Care (MOHLTC). The opinions, results and conclusions reported in this paper are those of the authors and are independent from the funding sources. No endorsement by ICES or the Ontario MOHLTC is intended or should be inferred. 